AGRICULTURE AND BIOLOGY JOURNAL OF NORTH AMERICA

ISSN Print: 2151-7517, ISSN Online: 2151-7525, doi:10.5251/abjna.2011.2.5.860.866

(C) 2011, ScienceHu $\beta$, http://www.scihub.org/ABJNA

\title{
Performance of Sudanese native Dwarf and Bare Neck Chicken raised under improved traditional production system
}

\author{
Yousif, I. A. ${ }^{1}$ and Eltayeb, N. $M^{2}$. \\ ${ }^{1}$ Department of Genetics and Animal Breeding, Faculty of Animal Production, University of \\ Khartoum, P.O.Box32 Khartoum North/Sudan \\ ${ }^{2}$ College of Veterinary Science University of West Kordufan Tel: 00249912691017. \\ P. O. Box 12942 Khartoum/Sudan E-mail nadagooda@yahoo.com \\ Corresponding author: Nada Mohammed Nour Eltayeb (nadagooda@yahoo.com)
}

\begin{abstract}
A total of 300 indigenous pullets of various ecotypes were used for phenotypic characterization of the native chicken of Sudan. This study aimed at evaluating production performance, egg characteristics and clutch traits of dwarf (Betwil) and Bare Neck ecotypes. Laying rate, average egg weight and egg components weights (albumen, yolk and shell) were significantly lower $(P<0.05)$ in dwarf (Betwil) than in Bare Neck. However yolk : albumen ratio and relative yolk weight were higher in dwarf (Betwil) than in Bare Neck. There were high and positive correlations between egg weight and egg components weights (albumen, yolk and shell) in both ecotypes, whereas the correlation between egg weight and shell thickness was low. The average number of egg per clutch, average clutch length and the number of clutch per year for dwarf (Betwil) were 9.89 eggs, 14.44 days and 5 clutches whereas the corresponding results for Bare Neck were 13.52 eggs, 20.04 days and 4 clutches. Hatchability from fertile eggs using natural incubation for dwarf (Betwil) and Bare Neck were 65.6 and 59.09 percent respectively. The observed oviposition patterns in both ecotypes seemed to be irregular with pauses ranging from 1-3 days and most of the eggs were laid during the day period from $10 \mathrm{am}$ to $2 \mathrm{pm}$.
\end{abstract}

Keywords : Indigenous chicken, Egg characteristics, Oviposition, Reproductive traits, Sudan

\section{INTRODUCTION}

The main objective of poultry breeders in developing countries is to improve the production performance of the indigenous poultry in term of egg and meat. The Sudanese native chicken breed includes three main ecotypes, namely Large Baladi (LB), Bare Neck (BN) and dwarf Bitwel (BT). They are characterized by producing a few and small eggs resulting in low egg mass and poor prophetability compared to the exotic strains. In spite of this fact, the native chickens play a vital socioeconomic role in rural communities of Sudan. Mekki et al (2005) found that egg production and average egg weight in dwarf (BT) were $48.57 \%$ and $39.89 \mathrm{~g}$ respectively whereas the corresponding results in BN were $38.57 \%$ and $37.95 \mathrm{~g}$. This low production has been attributed to the inferior genetic makeup of the breed and the poor management under which the birds are raised (El Hadji Gueyye, 1998 and Tadelle et al, 2003). Egg characteristics are indicators of egg quality which is one of the main objectives of a breeding programme. Elamin et al (1998) reported that the albumin height, shell thickness and Hug unit of the Sudanese chicken raised under relatively improved management were 8.35mm, 3.68 micrometer and 99.02 percent, while Mekki et al (2005) found that the average egg shell thickness of (BT) and (BN) were $36.21 \pm 4.22$ and $36.21 \pm 4.08$ micrometer respectively. In a comparative study between Korean native chicken (KNC) and a commercial egg-type chicken Suk and Par (2001) reported significant differences in egg, albumen and shell weights between the two breeds, they also found that the larger eggs had a greater proportion of albumin, but lower proportion of yolk. Fertility and hatchability are affected by several factors including breed, mating systems and management (Austic and Nesheim, 1990). Elfaki (2000) reported that fertility and hatchability of the Sudanese local chicken ranged from 75.66 to 92.29 and 31.88 to 43.17 percent respectively. The objectives of the this work were to investigate egg characteristics and reproduction performance of dwarf Betwil (BT) and Bare Neck (BN) chicken ecotypes under relatively improved management. 


\section{MATERIALS AND METHODS}

Experimental Stock: A total of 300 native chickens including dwarf Betwil (BT) and Bare Neck (BN) were purchased primarily for research purpose from the rural area of central Sudan. The birds were selected according to the typical phenotypic characteristics of indigenous breed as described by Desai (1962).

Housing and Management: The birds were housed at the Poultry Houses in the Faculty of Animal Production, University of Khartoum. Before the start of the experiment the stock had passed through four weeks adaptation period during which the birds received prophylactic doses of antihelementics, anticoccidiosis, antibiotics, and multivitamins. They were also vaccinated against New Castle disease. All the birds were identified using leg bands, and randomly distributed into single breeding pens with approx $100 \times 90 \times 80 \mathrm{~cm}$ dimensions and provided with plastic feeders and waterers. For purpose of estimating genetic parameters, each three pullets from each ecotype were assigned randomly to mate with one cockerel in a rotational pattern. In addition to the natural day light, artificial light system consisted of electric bulbs was used to provide 4 hours extra light daily. Formulated layer ration containing $17.50 \%$ Crude Protein and $2750 \mathrm{Kcal} / \mathrm{kg}$ metabolic energy was provided ad- libitum and fresh water was continuously available.

Data Collection: The daily egg production and egg weight were recorded for each pullet during the experimental period which lasted for 32 weeks. Eggs were allowed to accumulate in the nest within the breeding pens and naturally incubated. On the other hand the effect of egg accumulation in the nest on oviposition pattern was studied by intentionally leaving eggs to accumulate in the nests for 35 days production period, and then by immediately collecting them from nests as they were laid during another 35 days production period in the same birds. Samples consisted of 400 eggs, (200 from each of BT and BN ecotypes) were collected on daily bases for two months toward the second half of the production period and immediately used for studying egg characteristics and quality. The parameters measured included egg weight (EW), egg length $(E L)$, egg diameter (ED), shell thickness (ST), shell weight (SW), yolk height ( $\mathrm{YH})$, yolk diameter (YD), yolk weight (YW), albumin height $(\mathrm{AH})$ and albumin weight (AW). Eggs were carefully broken into two halves and the contents were gently poured on a flat horizontal glass, and the albumen and the yolk were carefully separated to measure their respective weight and height (Mogesse 2007). The egg shell including the membrane was also weighed after being dried under room temperature, however the membrane was removed carefully before measuring the egg shell thickness which was then measured as the average of three points (narrow end, middle and wide end). All these measures were taken using electronic digital caliper and electronic balance with readability of $0.01 \mathrm{~mm}$ and $0.01 \mathrm{~g}$ respectively.

Fertility and hatchability of the naturally incubated eggs were also calculated. The age at sexual maturity was determined for each hen by the first egg laid. The average egg number per clutch (ENC) and clutch length $(C L)$ were also recorded. Clutch length was determined as the number of days in a laying sequence including the pause days, whereas the egg number per clutch was calculated as the number of eggs laid within the clutch. The maximum egg number per clutch was also recorded.

Data analysis was performed according to Steel et al (1997) using Statistical Package for Social Science (SPSS) software version 11.5. The model used was

$Y_{i j}=\mu+B_{i}+e_{i j}$ Where:

$Y=$ single observation on the $j^{\text {th }}$ individual in the $i^{\text {th }}$ ecotype

$\mu=$ overall mean

$B_{i}=$ the effect of the $i^{\text {th }}$ breed (ecotype), $i=1,2$

$\mathrm{e}=$ the random error associated with single observation.

\section{RESULTS}

Table (1) presents egg production and egg weights of BT and BN chicken. The results revealed significant differences $(P<0.05)$ in laying rate and overall average egg weight between the two ecotypes with BT being lower producer and laying lighter eggs than BN (39.32 vs $49.09 \%$ and 41.71 vs $45.4 \mathrm{~g}$ ). Moreover, the average egg weight after 32 weeks production was significantly $(P<0.05)$ heavier than the initial egg weight in both ecotypes. This increase represented 43.6 and 53.7 percents in $\mathrm{BT}$ and BN respectively. Significant differences $(P<0.05)$ between the two ecotypes were also reported for other egg traits (table 2) with the results being lower in BT than in BN. Moreover AW, YW and SW represented approximately 53.77, 33.08 and 13.15 percents of the total egg weight respectively in BN, while the corresponding results in BT were 52.79, 33.88 and 13.15 percents. On the other hand the yolk-albumen ratio was not significantly different $(P<0.05)$ between the two ecotypes $(0.649$ and 0.625 
respectively). Table (3) presents the phenotypic correlations between egg traits in BT and BN. The general trend exhibited high and positive correlations between EW and other egg characteristics including AW, YW and SW in both ecotypes. The highest correlation was between EW and AW, whereas the lowest correlation was between EW and ST. However low and negative correlations between some egg traits were also reported, in both $\mathrm{BN}$ and BT. Table (4) presents the reproductive traits in BT and $\mathrm{BN}$, the fertility and hatchability of naturally incubated eggs were significantly $(P<0.05)$ higher in $\mathrm{BT}$ than those in BN. Regarding the clutch traits, BT exhibited significantly lower $(P<0.05)$ average ENC and $\mathrm{CL}$ than $\mathrm{BN}$, whereas the maximum average (CL) and (ENC) were 24 days and 16 eggs respectively in $\mathrm{BT}$ while the corresponding results in BN were 32 days and 21 eggs. The age at sexual maturity was significantly $(P<0.05)$ lower in $B T$ than in
BN (163.9 vs 184.9 days). Figures 1, 2, 3 and 4 present a randomly selected samples of oviposition patterns in both BT and BN ecotypes these patterns were selected for the same birds while eggs were accumulated in nest and also when removed. In general the results exhibited irregular egg sequences and pause days between the consecutive eggs laid which ranged from1-3days. For $B N$, eggs accumulation in the nest resulted in a relatively clustered scatter and the egg laying was ceased at the $28^{\text {th }}$ day, however when eggs were regularly removed from the nest the scatter exhibited an extended pattern and egg laying was continued up to the $30^{\text {th }}$ day resulting in $30 \%$ increase in egg production. Similar trend was observed in BT however increase in egg production was $50 \%$. The results also revealed that all eggs were laid during the day light with high percent being laid between 8 am and $2 \mathrm{pm}$.

Table 1: Egg production and egg weight of BT and BN:-

\begin{tabular}{|c|c|c|c|c|}
\hline Trait & BT & C.V & BN & C.V \\
\hline HHP (\%) & $31.45+2.42^{\mathrm{b}}$ & 0.24 & $43.36+5.68^{\mathrm{C}}$ & 0.26 \\
\hline HDP (\%) & $39.32+2.95^{\mathrm{b}}$ & 0.31 & $49.09+4.78^{\mathrm{C}}$ & 0.29 \\
\hline IEW (g) & $29.03 \pm 1.71^{\mathrm{a}}$ & 0.07 & $29.54 \pm 1.80^{\mathrm{a}}$ & 0.05 \\
\hline EW24 (g) & $37.65 \pm 0.29^{\mathrm{b}}$ & 0.08 & $40.46 \pm 0.30^{\mathrm{C}}$ & 0.12 \\
\hline EW32 (g) & $41.71 \pm 0.30$ & 0.17 & $45.4 \pm 0.30$ & 0.09 \\
\hline
\end{tabular}

* $\mathrm{HHP}=$ hen housed production, $\mathrm{HDP}=$ hen day production, $\mathrm{AEN}=$ average egg number, IEW = initial egg weight, $\mathrm{EW} 24=$ egg weight at week 24, EW32 = egg weight at week 32.

*Means with different superscripts within the raw are significantly different $(\mathrm{P}<0.01)$

* BT= Betwil; BN= Bare Neck chicken ecotypes

Table 2: Egg characteristics in BT and BN chicken ecotypes

\begin{tabular}{|c|c|c|c|c|}
\hline Trait & BT & C.V \% & $\mathrm{BN}$ & C.V \% \\
\hline Egg weight (g) & $41.71+0.31^{a}$ & 11.50 & $45.40+0.31^{b}$ & 8.87 \\
\hline Egg length (mm) & $50.15 \pm 0.21^{a}$ & 6.62 & $50.86 \pm 0.21^{b}$ & 5.31 \\
\hline Egg diameter(mm) & $38.17 \pm 0.16^{\mathrm{a}}$ & 7.33 & $40.07 \pm 0.16^{b}$ & 4.24 \\
\hline Albumin height(mm) & $7.18 \pm 0.06^{\mathrm{a}}$ & 11.55 & $7.57 \pm 0.06^{b}$ & 11.22 \\
\hline Albumin weight (g) & $22.09 \pm 0.22^{\mathrm{a}}$ & 15.07 & $24.41 \pm 0.22^{b}$ & 12.54 \\
\hline Yolk height (mm) & $16.49 \pm 0.08^{\mathrm{a}}$ & 6.97 & $16.75 \pm 0.08^{b}$ & 7.70 \\
\hline Yolk diameter (mm) & $37.15 \pm 0.21^{\mathrm{a}}$ & 6.86 & $37.96 \pm 0.21^{b}$ & 8.90 \\
\hline Yolk weight (g) & $14.13 \pm 0.14^{\mathrm{a}}$ & 13.88 & $15.02 \pm 0.14^{\mathrm{D}}$ & 13.84 \\
\hline Shell thickness (mm) & $0.386 \pm 0.003^{\mathrm{a}}$ & 0.75 & $0.395 \pm 0.003^{b}$ & 1.23 \\
\hline Shell weight (g) & $5.48 \pm 0.05^{\mathrm{a}}$ & 15.51 & $5.97 \pm 0.06^{b}$ & 13.75 \\
\hline Hug number (\%) & $74.01 \pm 0.47^{\mathrm{a}}$ & 9.24 & $77.81 \pm 0.46^{b}$ & 8.09 \\
\hline
\end{tabular}

*Means with different superscripts within the raw are significantly different $(\mathrm{P}<0.05)$

${ }^{*} \mathrm{BT}=$ Betwil; BN= Bare Neck chicken ecotypes. 
Agric. Biol. J. N. Am., 2011, 2(5): 860-866

Table 3: Phenotypic correlations between egg characteristics of BT and BN:-

\begin{tabular}{|l|l|l|l|l|l|l|l|l|l|l|l|l|}
\hline Ecotype & Parameter & EW & EL & ED & AH & YH & YD & YW & SHW & AW & HU & ST \\
\hline BT & EW & 1.00 & 0.77 & 0.45 & 0.35 & 0.45 & 0.47 & 0.66 & 0.73 & 0.88 & 0.74 & 0.19 \\
BN & & 1.00 & 0.38 & 0.53 & 0.36 & 0.43 & 0.26 & 0.50 & 0.69 & 0.79 & 0.69 & 0.04 \\
\hline BT & EL & & 1.00 & 0.43 & 0.19 & 0.37 & 0.50 & 0.57 & 0.54 & 0.64 & 0.55 & 0.17 \\
BN & & & 1.00 & 0.23 & 0.29 & 0.41 & 0.14 & 0.14 & 0.18 & 0.36 & 0.17 & -0.01 \\
\hline BT & ED & & & 1.00 & 0.07 & 0.12 & 0.19 & 0.32 & 0.39 & 0.37 & 0.35 & 0.10 \\
BN & & & & 1.00 & 0.12 & 0.28 & 0.18 & 0.35 & 0.37 & 0.36 & 0.37 & -0.05 \\
\hline BT & AH & & & & 1.00 & 0.32 & 0.04 & 0.01 & 0.26 & 0.44 & 0.26 & -0.12 \\
BN & & & & & 1.00 & 0.44 & -0.05 & -0.09 & 0.21 & 0.49 & 0.21 & 0.06 \\
\hline BT & YH & & & & & 1.00 & 0.25 & 0.28 & 0.35 & 0.41 & 0.34 & 0.03 \\
BN & & & & & & 1.00 & 0.18 & 0.20 & 0.21 & 0.37 & 0.20 & 0.06 \\
\hline BT & YD & & & & & & 1.00 & 0.56 & 0.27 & 0.29 & 0.28 & 0.04 \\
BN & & & & & & & 1.00 & 0.51 & 0.15 & -0.05 & 0.16 & -0.08 \\
\hline BT & YW & & & & & & & 1.00 & 0.48 & 0.25 & 0.50 & 0.14 \\
BN & & & & & & & & 1.00 & 0.31 & -0.11 & 0.32 & -0.08 \\
\hline BT & SHW & & & & & & & & 1.00 & 0.52 & 0.99 & 0.32 \\
BN & & & & & & & & & 1.00 & 0.43 & 0.99 & 0.16 \\
\hline BT & AW & & & & & & & & & 1.00 & 0.53 & 0.12 \\
BN & & & & & & & & & & & 1.00 & 0.33 \\
\hline BT & HU & & & & & & & & & & 1.00 & 0.17 \\
BN & & & & & & & & & & & & 1.00 \\
\hline BT & ST & & & & & & & & & & & 1.00 \\
BN & & & & & & & & & & & & \\
\hline
\end{tabular}

*EW, EL, ED, AH, YH, YD, YW, SHW, AW, HU and ST= egg weight, egg length, egg diameter, albumin height, yolk height, yolk diameter, yolk weight, shell weight, albumin weight, hug unit and shell thickness respectively.

Table 4: Reproductive performance and clutch traits in BT and BN

\begin{tabular}{|l|c|c|c|c|}
\hline Trait & BT & C.V & BN & C.V \\
\hline Fertility (\%) & $76.08 \pm 4.19^{\mathrm{b}}$ & 2.6 & $71.31 \pm 4.63^{\mathrm{c}}$ & 3.0 \\
\hline Hatchability from total eggs (\%) & $50.76 \pm 4.82^{\mathrm{b}}$ & 4.3 & $48.56 \pm 4.40^{\mathrm{c}}$ & 4.3 \\
\hline Hatchability from fertile eggs (\%) & $65.6+5.17^{\mathrm{b}}$ & 3.4 & $59.09+5.00^{\mathrm{c}}$ & 3.7 \\
\hline Age at first egg (days) & $163.90 \pm 1.55^{\mathrm{a}}$ & 0.75 & $184.90 \pm 1.71^{\mathrm{b}}$ & 0.71 \\
\hline Average clutch length (days) & $14.44 \pm 0.83^{\mathrm{a}}$ & 29.8 & $20.04 \pm 1.2^{\mathrm{b}}$ & 28.7 \\
\hline Average egg number per clutch (eggs) & $9.89 \pm 0.62^{\mathrm{a}}$ & 7.9 & $13.52 \pm 0.73^{\mathrm{b}}$ & 6.3 \\
\hline Hatched chicks per clutch (chicks) & $4.00 \pm 0.45$ & 16.7 & $4.04 \pm 0.53$ & 18.1 \\
\hline Dead in shell per clutch (chicks) & $1.62 \pm 0.25^{\mathrm{a}}$ & 30.8 & $2.38 \pm 0.29^{\mathrm{b}}$ & 22.6 \\
\hline Broken eggs per clutch (eggs) & $2.10 \pm 0.67^{\mathrm{a}}$ & 38.9 & $5.85 \pm 0.78^{\mathrm{b}}$ & 15.1 \\
\hline Infertile eggs per clutch (eggs) & $1.17 \pm 0.37^{\mathrm{a}}$ & 28.0 & $2.23 \pm 0.44^{\mathrm{b}}$ & 53.9 \\
\hline
\end{tabular}

Means with different superscript letters within the raw are significantly different $(P<0.05)$.

* BT= Betwil; BN= BN chicken ecotypes. 


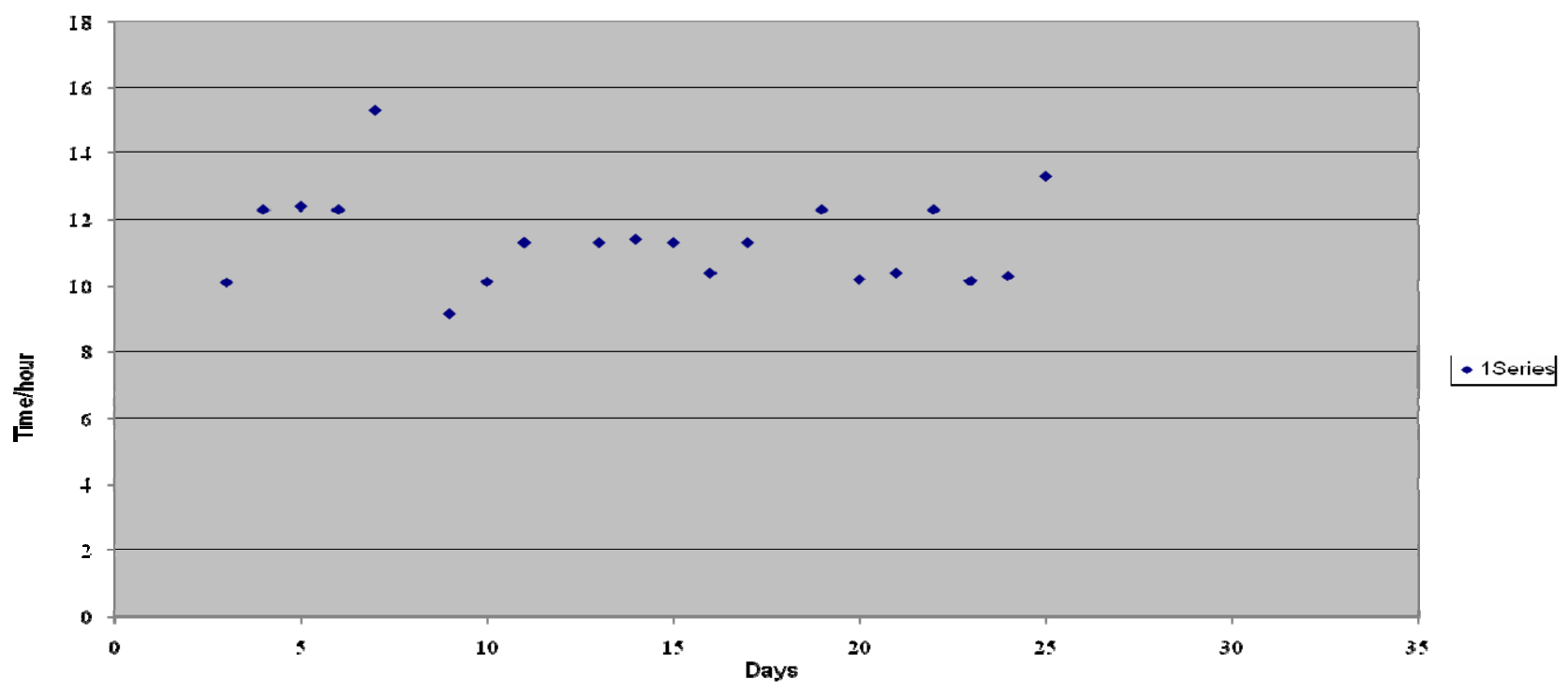

Fig 1: Oviposition pattern in Bare Neck ecotype while eggs were accumulated in the nest

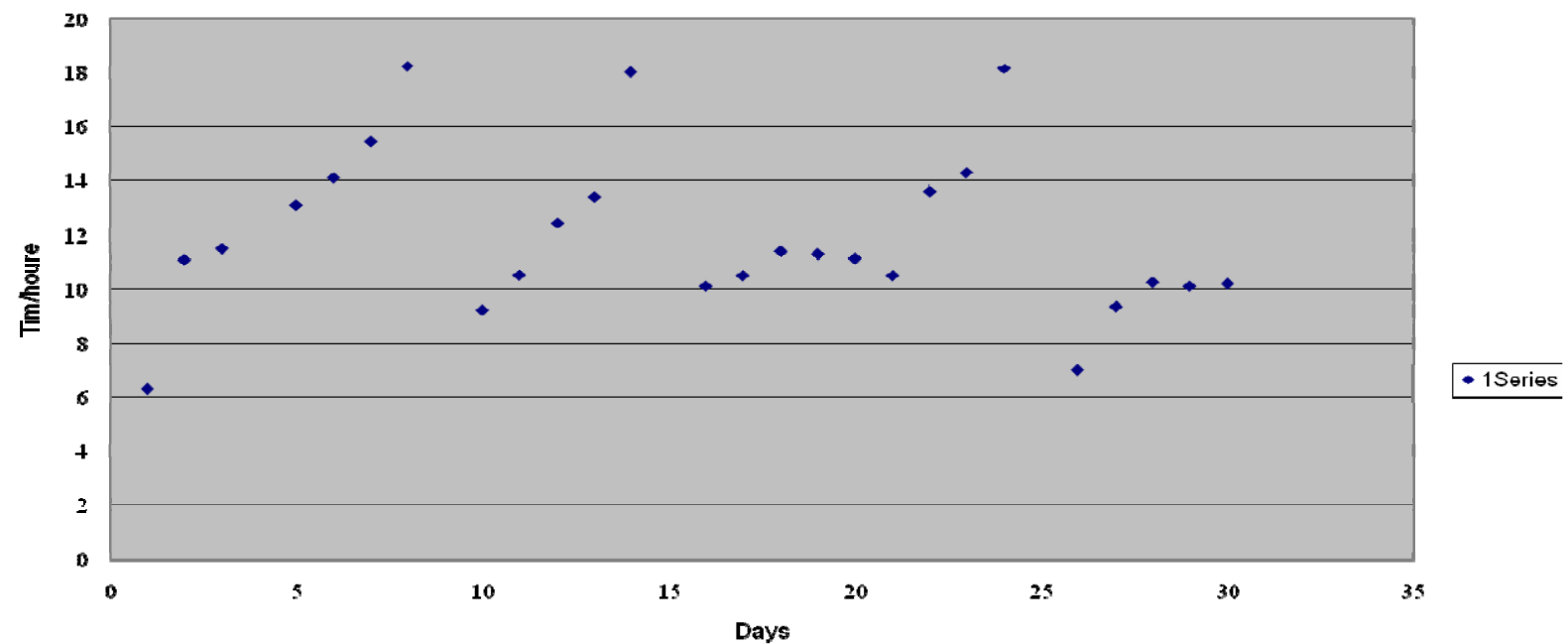

Fig 2: Oviposition pattern in Bare Neck ecotype while eggs were removed from the nest 
Agric. Biol. J. N. Am., 2011, 2(5): 860-866

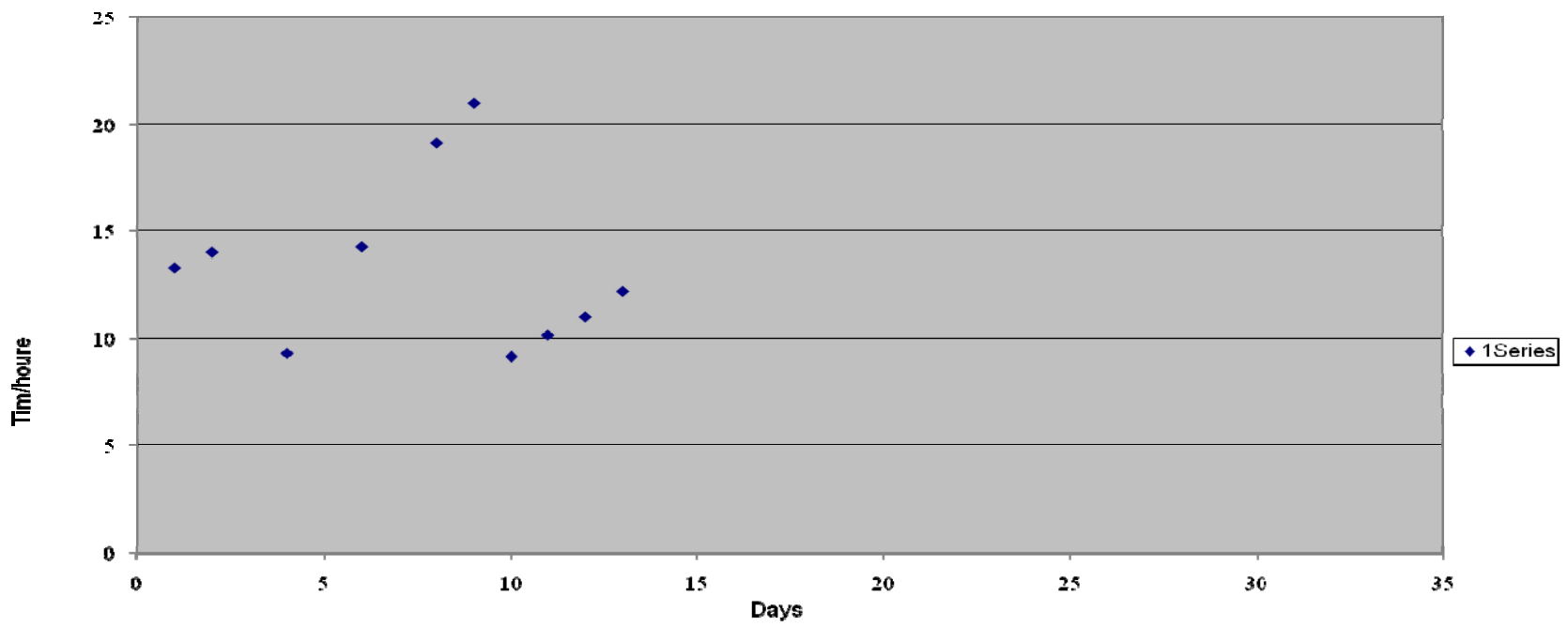

Fig 3: Oriposition pattern in Betwil ecotype while eggs were accumulated in the nest

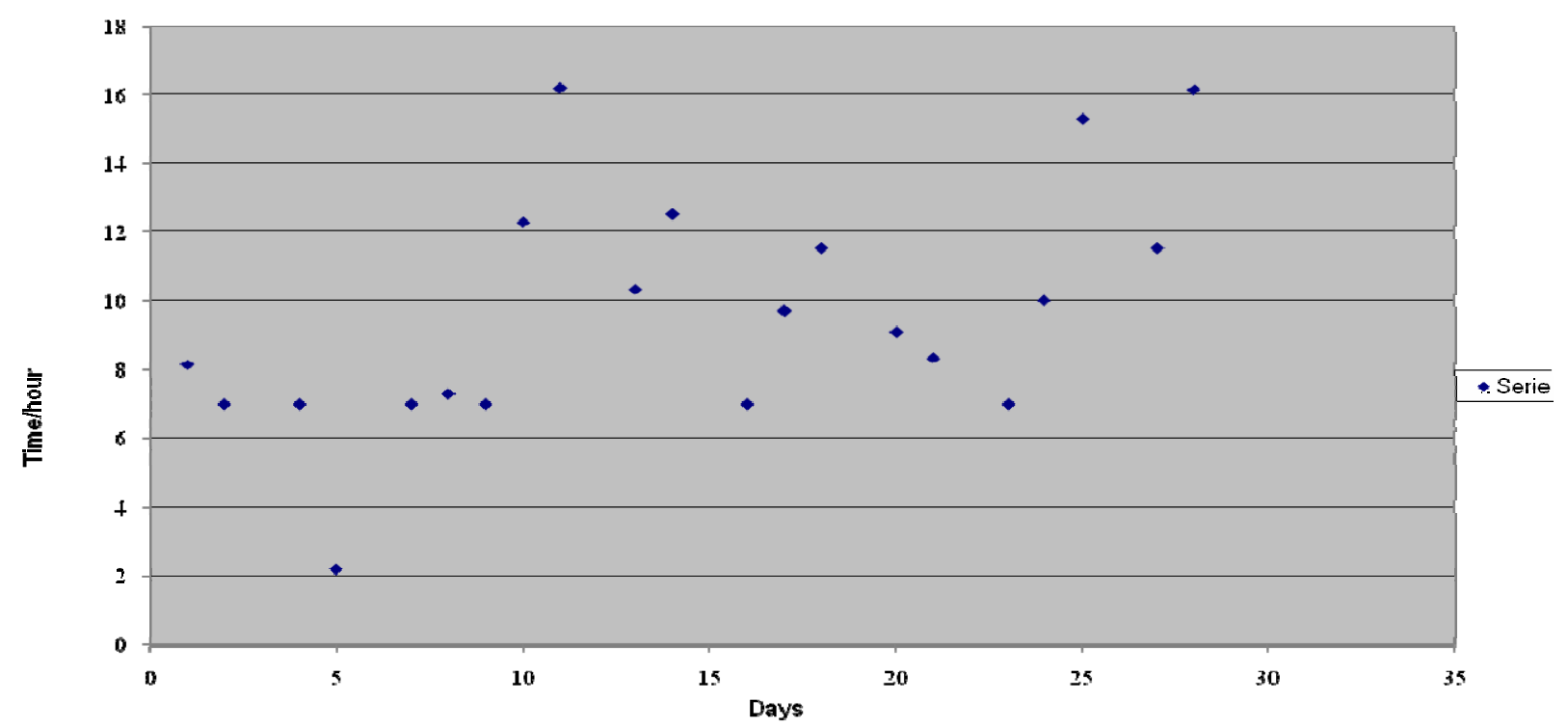

Fig 4: Oviposition pattern in Betwil ecotype while eggs were removed from the nest 


\section{DISCUSSION}

The present study revealed that laying rate and egg weight in BT were significantly lower than those in BN. This may indicate the negative impact of sex linked dwarf gene on production performance. Missohou et al (2002) found that the total egg number and egg weight of layers were significantly reduced (18 and 9 percent respectively) by dwarf genes. Furthermore egg weight exhibited a substantial increase with advance age in both BT and $\mathrm{BN}$. This result is in accordance with those reported by Singh et al (2009) and Tactacan et al (2009). Generally the performances of $\mathrm{BT}$ and $\mathrm{BN}$ in this study are within the range of those reported for the indigenous chickens (Mekki et al, 2005; and Ershad, 2005) however they are significantly lower than the exotic layer strains. This should be expected since there has been no considerable effort exerted to improve the genetic potential of the native chicken of Sudan.

Egg weight has strong relationships with other egg components. As shown in this study there were high and positive correlations between egg weight and egg components (albumen, yolk and shell weights) which emphasize that selection for increased egg weight will ultimately result in increase weights of the various egg components. Albumen, yolk and shell weights were significantly lower in BT than in BN, however the reverse was true for yolk as a relative weight of the whole egg (33.9 vs 33.1) and yolk to albumen ratio (0.64 vs 0.62 ). Possibly this may indicate that the proportions of egg components in BT are different than in $\mathrm{BN}$. On the other hand the relative yolk weights in this study were higher than the results reported by Singh et al (2009) in four strains of laying hens at 30 weeks of production. Similarly Suck and Park (2001) found high yolk weight and heavier yolk to albumen ratio in Korean native chicken compared to a commercial egg-type chicken. These differences in egg components between the exotic strains and the indigenous chicken breeds may be attributed to the selection pressure exerted on exotics while the native chickens are still maintaining their wild characteristics.

\section{CONCLUSION}

Although they are less productive compared with the exotics, the performance of the Sudanese BT and BN were within the average of the results reported for the indigenous chicken in developing countries. There were a substantial variation in egg performance and characteristics between BT and BN ecotypes; these may need to be considered while setting a strategy for improving the indigenous chicken of Sudan. Due to broody nature of the indigenous chicken, BT and BN can achieve only 5 and 4 clutches per year respectively.

The high proportion of yolk and yolk to albumen ratio in BT and BN may present eggs from these ecotypes as being more suitable for processing than being used as table eggs.

\section{REFERENCES}

Desai, D. K. (1962). The status importance and development of poultry keeping. Sudan $\mathrm{J}$ of Vet. Sci and Anim. Husb 4 (3):140-143.

Elamin, K. M. (1998) Estimation of genetic and phenotypic parameters for egg production traits of the chicken. Thesis, Faculty of Animal prod. U. of K.

Elfaki , A. E.(2000) Comparative study on the performance of five Large Baladi native fowl groups and white Hisex under relatively improved condition. MSc. Thesis, Faculty of Animal prod. U. of K.

El hadji, F. Gueye. (1998)Village egg and fowl meat production in Africa. World Poult. Sci. J. Vol. 54.

Ershad, S. M. E. (2005) Performance of hybrid layers and native hens under farms management in selected area of Bangladesh. International J. of Poult. Sci. 4(4):228232.

Mekki, D. M. Yousif, I. A. Abdel Rahman, M. K. Wang, J and Mussa, M. H. (2005) Comparison of the egg Characteristics of different Sudanese indigenous chicken ecotype. International J. of Poult. Sci 4(7):455-457.

Missohou, A. Dieye, P. N and Talaki, E. (2002) Rural poultry production and productivity in southern Senegal. Livestock Research for Rural Development 14 (2).

Austic, R.E. and M.C. Nesheim. 1990. In: Poultry Production. 13th Edition. Lea \& Febiger. Philadelphia, London. pp. 47-55.

Suk, Y. O. and Park, C. (2001) Effect of Breed and Age of Hen on the Yolk to Albumin Ratio in Two Different Genetic Stocks. Poultry Science 80:855-858

Tadelle, D and Peters, k. J. (2003) Indigenous chicken ecotypes in Ethiopia: growth and feed utilization potentials. International J. of Poult. Sci. 2(2):144152. 